\title{
Solar-blind AIGaN-based Schottky photodiodes with low noise and high detectivity
}

Necmi Biyikli, Orhan Aytur, Ibrahim Kimukin, Turgut Tut, and Ekmel Ozbay

Citation: Appl. Phys. Lett. 81, 3272 (2002); doi: 10.1063/1.1516856

View online: http://dx.doi.org/10.1063/1.1516856

View Table of Contents: http://aip.scitation.org/toc/apl/81/17

Published by the American Institute of Physics

\section{Articles you may be interested in}

Solar-blind AIGaN photodiodes with very low cutoff wavelength

Applied Physics Letters 76, 403 (2000); 10.1063/1.125768

High quantum efficiency AIGaN solar-blind $p-i-n$ photodiodes

Applied Physics Letters 84, 1248 (2004); 10.1063/1.1650550

Improved solar-blind detectivity using an $\mathrm{Al}_{x} \mathrm{Ga}_{1-\mathrm{x}} N$ heterojunction $\mathrm{p}-\mathrm{i}-\mathrm{n}$ photodiode

Applied Physics Letters 80, 3754 (2002); 10.1063/1.1480484

Gain mechanism in GaN Schottky ultraviolet detectors

Applied Physics Letters 79, 1417 (2001); 10.1063/1.1394717

Solar-blind AIGaN-based inverted heterostructure photodiodes

Applied Physics Letters 77, 316 (2000); 10.1063/1.126962

Role of self-trapped holes in the photoconductive gain of $\beta$-gallium oxide Schottky diodes

Journal of Applied Physics 119, 103102 (2016); 10.1063/1.4943261

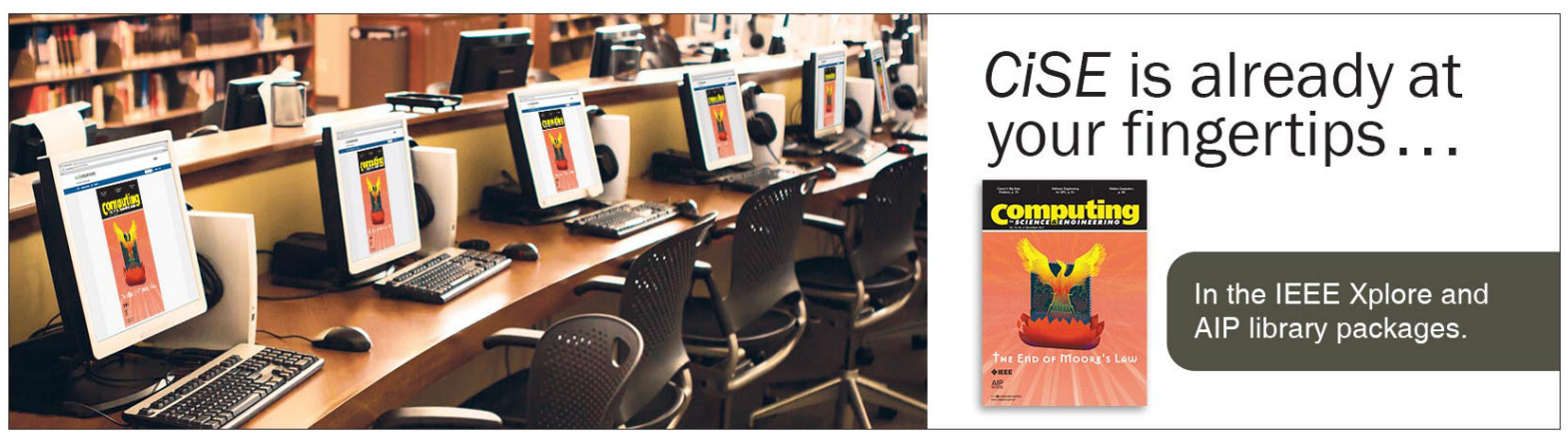




\title{
Solar-blind AIGaN-based Schottky photodiodes with low noise and high detectivity
}

\author{
Necmi Biyiklia) and Orhan Aytur \\ Department of Electrical and Electronics Engineering, Bilkent University, Bilkent Ankara 06533, Turkey \\ Ibrahim Kimukin, Turgut Tut, and Ekmel Ozbay \\ Department of Physics, Bilkent University, Bilkent Ankara 06533, Turkey
}

(Received 11 July 2002; accepted 27 August 2002)

\begin{abstract}
We report on the design, fabrication, and characterization of solar-blind Schottky photodiodes with low noise and high detectivity. The devices were fabricated on $n-/ n+\mathrm{AlGaN} / \mathrm{GaN}$ heterostructures using a microwave compatible fabrication process. True solar-blind operation with a cutoff wavelength of $\sim 274 \mathrm{~nm}$ was achieved with $\mathrm{Al}_{x} \mathrm{Ga}_{1-x} \mathrm{~N}(x=0.38)$ absorption layer. The solar-blind detectors exhibited $<1.8 \mathrm{nA} / \mathrm{cm}^{2}$ dark current density in the $0-25 \mathrm{~V}$ reverse bias regime, and a maximum quantum efficiency of $42 \%$ around $267 \mathrm{~nm}$. The photovoltaic detectivity of the devices were in excess of $2.6 \times 10^{12} \mathrm{~cm} \mathrm{~Hz}^{1 / 2} / \mathrm{W}$, and the detector noise was $1 / f$ limited with a noise power density less than $3 \times 10^{-29} \mathrm{~A}^{2} / \mathrm{Hz}$ at $10 \mathrm{kHz}$. (C) 2002 American Institute of Physics.
\end{abstract}

[DOI: $10.1063 / 1.1516856]$

Photodetectors that operate only in the $\lambda<280 \mathrm{~nm}$ spectrum are named as solar-blind detectors due to their blindness to solar radiation within the atmosphere. ${ }^{1}$ Solar-blind photodetectors are essential components for a number of applications including missile plume detection, flame/engine control, and chemical/biological agent sensing. $\mathrm{Al}_{x} \mathrm{Ga}_{1-x} \mathrm{~N}$-based photodetectors potentially offer significant advantages over the current photomultiplier tube and siliconbased solar-blind detector technology in terms of size, complexity, cost, robustness, stability, power demands, and bandwidth. $^{2}$ Moreover, its intrinsic solar blindness (for $x$ $\geqslant 0.38$ ) and the ability of operation under harsh conditions (high-temperature and high power levels) due to its wide band gap makes $\mathrm{Al}_{x} \mathrm{Ga}_{1-x} \mathrm{~N}$-based photodetectors attractive for high-performance solar-blind detection applications. Several research groups have demonstrated successful solarblind operation with $\mathrm{Al}_{x} \mathrm{Ga}_{1-x} \mathrm{~N}$ photodetectors using photoconductive, ${ }^{3,4} \quad p-i-n,{ }^{5-14}$ metal-semiconductormetal (MSM), ${ }^{15,16}$ and Schottky ${ }^{17-20}$ detector structures. Cutoff wavelengths $\left(\lambda_{c}\right)$ as short as $\sim 225 \mathrm{~nm}$, an ultraviolet/ visible rejection over 5 orders of magnitude along with responsivities as high as $0.12 \mathrm{~A} / \mathrm{W}$ at $232 \mathrm{~nm}$ were reported using a $\mathrm{Al}_{0.7} \mathrm{Ga}_{0.3} \mathrm{~N} p-i-n$ detector structure. ${ }^{6,11} \mathrm{Al}_{0.5} \mathrm{Ga}_{0.5} \mathrm{~N}$ MSM photodiodes with a noise equivalent power (NEP) as low as $30 \mathrm{fW}$ at $280 \mathrm{~nm}$ and detectivity of 2.5 $\times 10^{13} \mathrm{~cm} \mathrm{~Hz}^{1 / 2} / \mathrm{W}$ correspond to the best noise performance achieved for AlGaN-based solar-blind detectors. ${ }^{15}$ Dark currents less than $2 \mathrm{pA}$ at $30 \mathrm{~V}$ reverse bias and a $3 \mathrm{~dB}$ bandwidth of $100 \mathrm{MHz}$ was reported for a $\mathrm{Al}_{0.4} \mathrm{Ga}_{0.6} \mathrm{~N}$ MSM structure. ${ }^{16} \mathrm{Al}_{0.35} \mathrm{Ga}_{0.65} \mathrm{~N} p-i-n$ photodiodes on $\mathrm{SiC}$ substrates with low leakage currents were also successfully demonstrated. $^{12}$

When compared with $p-i-n$ photodiodes, AlGaN Schottky photodiodes have several advantages. Growth of $p$-type doped AlGaN layers and formation of low resistance

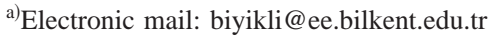

$p+$ ohmic contacts are two challenging issues for $p-i-n$ photodiodes, while Schottky photodiodes do not face these problems. Besides the ease of growth and fabrication, efficient collection of generated carriers within the junction and better high-frequency characteristics are the other advantages of AlGaN Schottky photodiodes. However, they lack from low efficiency mainly due to the optical absorption introduced by the thin Schottky metal, and exhibit high leakage currents and poor noise performance. The reported best detector performances obtained with solar-blind AlGaN Schottky photodiodes include a maximum responsivity of $0.07 \mathrm{~A} / \mathrm{W}$ at $290 \mathrm{~nm}$ along with a NEP of $6.6 \times 10^{-9} \mathrm{~W},{ }^{18}$ a minimum $\lambda_{c}$ of $278 \mathrm{~nm}$ and a minimum dark current density of $6.6 \times 10^{-6} \mathrm{~A} / \mathrm{cm}^{2} .{ }^{19}$ In this letter, we demonstrate low noise solar-blind AlGaN-based Schottky photodiodes with very low dark current and high detectivity.

The epitaxial structure of the front-illuminated Schottky detector wafer was designed to achieve true solar-blindness, low leakage, and high solar rejection. In order to meet these requirements, $\mathrm{Al}_{0.38} \mathrm{Ga}_{0.62} \mathrm{~N}$ absorption layer was used to achieve $\lambda_{c}<280 \mathrm{~nm}$. The $\mathrm{Al}_{x} \mathrm{Ga}_{1-x} \mathrm{~N} / \mathrm{GaN}$ epitaxial layers of our heterojunction Schottky photodiode wafer were grown on a 2 in. single-side polished (0001) sapphire substrate using metalorganic chemical vapor deposition. A thin AlN nucleation layer was first deposited followed by a $0.5 \mu \mathrm{m}$ thick unintentionally doped GaN mesa isolation layer. Afterward, a highly doped $\left(n^{+}=2 \times 10^{18} \mathrm{~cm}^{-3}\right)$ ohmic contact layer composed of $0.6 \mu \mathrm{m}$ thick $\mathrm{GaN}$ and $0.2 \mu \mathrm{m}$ thick $\mathrm{Al}_{0.38} \mathrm{Ga}_{0.62} \mathrm{~N}$ were grown, respectively. The growth of the Schottky heterostructure was completed with the deposition of a $0.8 \mu \mathrm{m}$ thick undoped $\mathrm{Al}_{0.38} \mathrm{Ga}_{0.62} \mathrm{~N}$ active layer. The highly doped GaN layer was used for ohmic contact region due to the difficulty of obtaining high-quality ohmic contacts with $\mathrm{Al}_{x} \mathrm{Ga}_{1-x} \mathrm{~N}$ layers. The $n$-type doped $0.2 \mu \mathrm{m}$ thick $\mathrm{Al}_{0.38} \mathrm{Ga}_{0.62} \mathrm{~N}$ layer was used as a diffusion barrier for the photocarriers generated in the GaN ohmic contact layer. Such a diffusion barrier is expected to increase the solarblind/near-UV rejection ratio of the detector. 


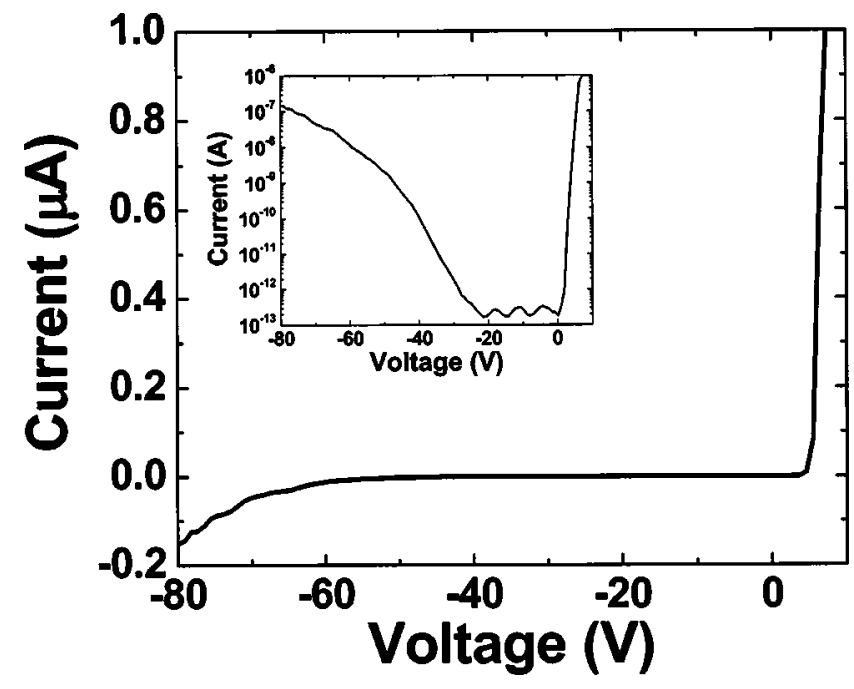

FIG. 1. ( $I-V)$ characteristics of a $150 \times 150 \mu \mathrm{m}^{2}$ solar-blind Schottky photodiode. Inset shows the same data plotted in logarithmic scale.

The samples were fabricated by using a four-step microwave-compatible fabrication process in a class-100 clean room environment. First, the ohmic contact regions were defined via reactive ion etching (RIE) under $\mathrm{CCl}_{2} \mathrm{~F}_{2}$ plasma, $20 \mathrm{sccm}$ gas flow rate, and $100 \mathrm{~W}$ rf power. The etch rates for $\mathrm{GaN}$ and $\mathrm{Al}_{0.38} \mathrm{Ga}_{0.62} \mathrm{~N}$ layers were determined as 300 and $80 \AA / \mathrm{min}$, respectively. After an ohmic etch of $\sim 1.3$ $\mu \mathrm{m}, \mathrm{Ti} / \mathrm{Al}(100 \AA / 1000 \AA)$ contacts were deposited via thermal evaporation and left in acetone solution for lift-off process. The contacts were annealed at $700^{\circ} \mathrm{C}$ for $30 \mathrm{~s}$ in a rapid thermal annealing system. Mesa structures of the devices were formed via the same RIE process, by etching all the layers $(>1.6 \mu \mathrm{m})$ down to the undoped GaN mesa isolation layer. Then, $\mathrm{a} \sim 100 \AA$ thick $\mathrm{Au}$ film was evaporated to form the Au/AlGaN Schottky contacts. Finally, a $\sim 0.7 \mu \mathrm{m}$ thick Ti/Au interconnect metal was deposited and lifted off to connect the Schottky layers to coplanar waveguide transmission line pads.

The resulting AlGaN Schottky photodiodes had breakdown voltages above $50 \mathrm{~V}$ and turn-on voltages around $2 \mathrm{~V}$. Figure 1 shows the current-voltage $(I-V)$ characteristics of a $150 \times 150 \mu \mathrm{m}^{2}$ device. The leakage current of the diodes was lower than $1 \mathrm{pA}$ for reverse bias voltages up to $30 \mathrm{~V}$. As can be observed in the logarithmic plot, the dark current fluctuated within 150-400 fA in the 0-25 V reverse bias range. The actual leakage values in this range could not be measured due to the measurement setup resolution. These leakage values correspond to dark current density values of $0.7-1.8 \mathrm{nA} / \mathrm{cm}^{2}$. Hence, we can safely claim that our solarblind detectors exhibited dark current densities lower than $1.8 \mathrm{nA} / \mathrm{cm}^{2}$ under reverse bias voltages as high as $25 \mathrm{~V}$. The differential resistance $(R=d V / d I)$ of our detectors was calculated and a dark impedance in excess of $10^{13} \Omega$ was obtained in the $0-25 \mathrm{~V}$ range.

Spectral photoresponse measurements were done in the 250-350 nm range, using a xenon lamp light source, a single-pass monochromator, a lock-in amplifier, and a calibrated $\mathrm{Si}$ photodetector. Figure 2(a) shows the measured spectral quantum efficiency under reverse bias voltages ranging from 0 to $50 \mathrm{~V}$. The quantum efficiency increased with reverse bias and reached a maximum value of $\sim 42 \%$ at 267
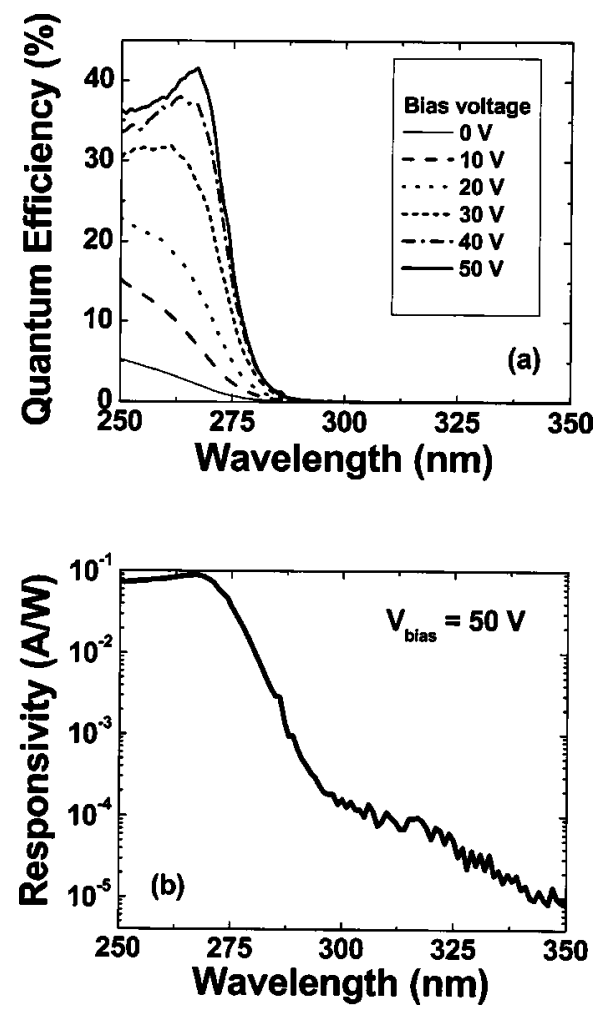

FIG. 2. (a) Measured spectral quantum efficiency of the AlGaN Schottky photodiode. (b) Corresponding responsivity curve of the device under $50 \mathrm{~V}$ reverse bias.

$\mathrm{nm}$ under $50 \mathrm{~V}$ reverse bias. The cutoff wavelength redshifted with reverse bias, from 266 to $274 \mathrm{~nm}$ for 0 and $50 \mathrm{~V}$ reverse bias, respectively. Since $\lambda_{c}<280 \mathrm{~nm}$ was satisfied, true solar-blind detection was successfully demonstrated. The corresponding device responsivity curve under $50 \mathrm{~V}$ reverse bias is shown in Fig. 2(b). A peak responsivity of 0.09 $\mathrm{A} / \mathrm{W}$ at $267 \mathrm{~nm}$ is measured. The responsivity drops sharply around $270 \mathrm{~nm}$ and a solar-blind/near-UV contrast of 4 orders of magnitude is observed within $80 \mathrm{~nm}$. To estimate the detectivity $\left(D^{*}\right)$ of our detectors in the photovoltaic mode, we have used the thermal-noise limited detectivity relation $D^{*}=R_{\lambda}\left(R_{0} A / 4 k T\right)$, where $R_{\lambda}$ is the device reponsivity at zero bias, $R_{0}$ is the zero volt dark impedance and $A$ is the detector area. With a $0.01 \mathrm{~A} / \mathrm{W}$ photovoltaic responsivity at $250 \mathrm{~nm}$, the zero-bias detectivity of our detectors were in excess of $2.6 \times 10^{12} \mathrm{~cm} \mathrm{~Hz}^{1 / 2} / \mathrm{W}$, which corresponds to a setup limited NEP of $5.8 \times 10^{-15} \mathrm{~W} / \mathrm{Hz}^{1 / 2}$.

Finally, noise characterization of the solar-blind Schottky detectors were carried out in the frequency range of $1 \mathrm{~Hz}-100 \mathrm{kHz}$ using a fast Fourier transform spectrum analyzer and a microwave probe station. Our low-leakage, highbreakdown voltage solar-blind detectors had noise power densities below the instrument resolution. Even under reverse bias as high as $25 \mathrm{~V}$, the detector noise did not exceed the measurement setup noise floor of $3 \times 10^{-29} \mathrm{~A}^{2} / \mathrm{Hz}$ around $10 \mathrm{kHz}$. Therefore, we have measured devices with higher leakage currents in order to observe the bias dependence of the spectral noise density. Figure 3 shows the lowfrequency spectral noise density of a $80 \mu \mathrm{m}$ diameter detector with $\sim 7$ orders of magnitude larger dark currents ( $>1 \mu \mathrm{A} @ 5 \mathrm{~V}$ ) and $\sim 14 \mathrm{~V}$ breakdown voltage. The spectral noise curves show that $1 / f$ noise is the dominant noise 


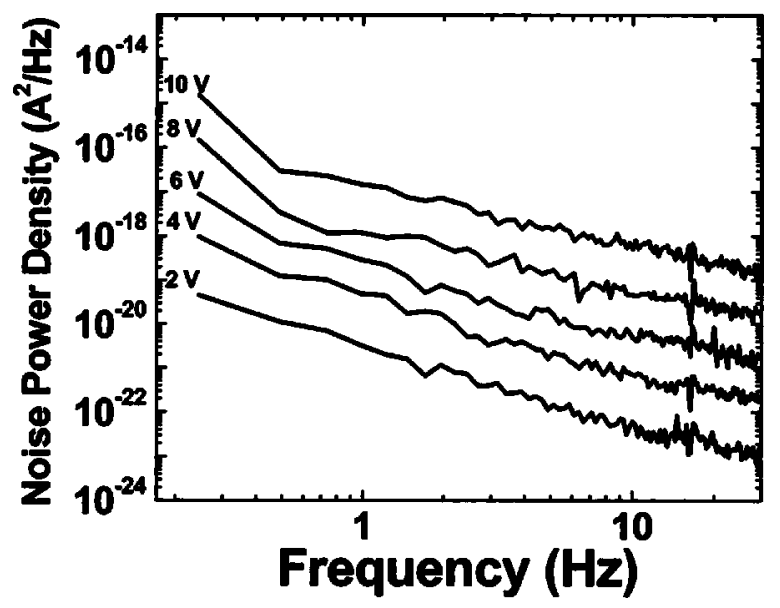

FIG. 3. Low-frequency spectral noise measurements of a high-leakage 80 $\mu \mathrm{m}$ diameter Schottky photodiode as a function of applied reverse bias.

mechanism in our detectors, as is common for Schottky barrier AlGaN detectors at low frequencies. $S_{n}(f)$ values of $\sim 8 \times 10^{-23} \mathrm{~A}^{2} / \mathrm{Hz}$ at $30 \mathrm{~Hz}$ under $2 \mathrm{~V}$ increased up to $\sim 10^{-19} \mathrm{~A}^{2} / \mathrm{Hz}$ for $10 \mathrm{~V}$ bias. The noise curves obey the $S_{n}=S_{0} / f^{\gamma}$ relation with the fitting parameter $\gamma$ varying from 0.9 to 1.2 .

In summary, we have demonstrated solar-blind AlGaNbased Schottky photodiodes with low dark current, low noise, and high detectivity. Breakdown voltages larger than $50 \mathrm{~V}$ and dark currents less than $400 \mathrm{fA}$ under $25 \mathrm{~V}$ reverse bias were achieved. $I-V$ characteristics of the solar-blind detectors led to the lowest dark current density $\left(<1.8 \mathrm{nA} / \mathrm{cm}^{2}\right)$ and the highest detectivity $(>2.6$ $\left.\times 10^{12} \mathrm{~cm} \mathrm{~Hz}^{1 / 2} / \mathrm{W}\right)$ values reported for solar-blind AlGaN Schottky photodiodes. Device responsivities as high as 0.09 $\mathrm{A} / \mathrm{W}$ were measured under $50 \mathrm{~V}$ reverse bias. Detector noise was $1 / f$ limited with spectral noise density values less than $3 \times 10^{-29} \mathrm{~A}^{2} / \mathrm{Hz}$ under reverse bias voltages as high as $25 \mathrm{~V}$.

This work was supported by NATO Grant No. SfP971970, Turkish Department of Defense Grant No. KOBRA-001, and Thales Grant No. JP8.04.
${ }^{1}$ P. Schreiber, T. Dang, G. Smith, T. Pickenpaugh, P. Gehred, and C. Litton, Proc. SPIE 3629, 230 (1999).

${ }^{2}$ J. C. Carrano, T. Li, P. A. Grudowski, R. D. Dupuis, and J. C. Campbell, IEEE Circuits Devices Mag. 15, 15 (1999).

${ }^{3}$ D. Walker, X. Zhang, P. Kung, A. Saxler, S. Javapour, J. Xu, and M. Razeghi, Appl. Phys. Lett. 68, 2100 (1996).

${ }^{4}$ B. W. Lim, Q. C. Chen, J. Y. Yang, and M. Asif Khan, Appl. Phys. Lett. 68, 3761 (1996).

${ }^{5}$ G. Parish, S. Keller, P. Kozodoy, J. P. Ibbetson, H. Marchand, P. T. Fini, S. B. Fleischer, S. P. Denbaars, U. K. Mishra, and E. J. Tarsa, Appl. Phys. Lett. 75, 247 (1999).

${ }^{6}$ D. Walker, V. Kumar, K. Mi, P. Sandvik, P. Kung, X. H. Zhang, and M. Razeghi, Appl. Phys. Lett. 76, 403 (2000).

${ }^{7}$ E. J. Tarsa, P. Kozodoy, J. Ibbetson, B. P. Keller, G. Parish, and U. Mishra, Appl. Phys. Lett. 77, 316 (2000).

${ }^{8}$ D. J. H. Lambert, M. M. Wong, U. Chowdhury, C. Collins, T. Li, H. K. Kwon, B. S. Shelton, T. G. Zhu, J. C. Campbell, and R. D. Dupuis, Appl. Phys. Lett. 77, 1900 (2000).

${ }^{9}$ J. D. Brown, J. Li, P. Srinivasan, J. Matthews, and J. F. Schetzina, MRS Internet J. Nitride Semicond. Res. 5, 9 (2000).

${ }^{10}$ M. M. Wong, U. Chowdhury, C. J. Collins, B. Yang, J. C. Denyszyn, K. S. Kim, J. C. Campbell, and R. D. Dupuis, Phys. Status Solidi A 188, 333 (2001).

${ }^{11}$ P. Sandvik, K. Mi, F. Shahedipour, R. McClintock, A. Yasan, P. Kung, and M. Razeghi, J. Cryst. Growth 231, 366 (2001).

${ }^{12}$ G. Parish, M. Hansen, B. Moran, S. Keller, S. P. Denbaars, and U. K. Mishra, Phys. Status Solidi A 188, 297 (2001).

${ }^{13}$ A. Hirano, C. Pernot, M. Iwaya, T. Detchprohm, H. Amano, and I. Akasaki, Phys. Status Solidi A 188, 293 (2001).

${ }^{14}$ J. C. Campbell, C. J. Collins, M. M. Wong, U. Chowdhury, A. L. Beck, and R. D. Dupuis, Phys. Status Solidi A 188, 283 (2001).

${ }^{15}$ J. Y. Duboz, J. L. Reverchon, D. Adam, B. Damilano, F. Semond, N. Grandjean, and J. Massies, Phys. Status Solidi A 188, 325 (2001).

${ }^{16}$ T. Li, J. H. Lambert, A. L. Beck, C. J. Collins, B. Yang, M. M. Wong, U. Chowdhury, R. D. Dupuis, and J. C. Campbell, J. Electron. Mater. 30, 872 (2001).

${ }^{17}$ A. Osinsky, S. Gangopadhyay, B. W. Lim, M. Z. Anwar, M. A. Khan, D. V. Kuksenkov, and H. Temkin, Appl. Phys. Lett. 72, 742 (1998).

${ }^{18}$ S. L. Rumyantsev, N. Pala, M. S. Shur, R. Gaska, M. E. Levinshtein, V. Adivarahan, J. Yang, G. Simin, and M. Asif Khan, Appl. Phys. Lett. 79, 866 (2001).

${ }^{19}$ V. Adivarahan, G. Simin, G. Tamulaitis, R. Srinivasan, J. Yang, M. Asif Khan, M. S. Shur, and R. Gaska, Appl. Phys. Lett. 79, 1903 (2001).

${ }^{20}$ E. Monroy, F. Calle, J. L. Pau, F. J. Sanchez, E. Munoz, F. Omnes, B. Beaumont, and P. Gibart, J. Appl. Phys. 88, 2081 (2000). 